\title{
Most Common Type of Corrective Feedback in Iranian Classrooms
}

\author{
Leily Nekuruhmotlagh \\ Shiraz Azad University, Shiraz, Iran
}

\begin{abstract}
The current study aims to explore Iranian EFL teachers' preferences for oral corrective feedback; if they choose different types of feedback to correct students' errors or if they provide students with the same type of feedback. This study also tried to investigate if teachers allow peer-feedback in class. To do so, a questionnaire was distributed to 62 EFL Iranian teachers, to choose their preferences for feedback and the feedback provider. The results of the study showed that 43 teachers used the same type of corrective feedback for all error types, and that they preferred implicit types of corrective feedback over the explicit ones. The results also indicated that 13 teachers believed peer and self-corrections were not beneficial. Some teachers felt other factors might also affect their choice of feedback provider or the type of feedback they use in their classes.
\end{abstract}

Key words: corrective feedback, teacher, peer correction, implicit feedback, explicit feedback. 


\section{Introduction}

As the focus of classroom instruction has shifted over the past few decades from an emphasis on language forms to functional language within communicative context, the question of the place of error correction or corrective feedback (CF), has become more and more important (Brown, 2004). The role of errors in the language learning process has interested researchers since the 1970s when Error Analysis became a popular paradigm for studying foreign and second language learning and teaching. Moving away from the more traditional view of contrastive analysis to the new favored view of error analysis shifted the focus of the teachers and researchers from studying the relationship between the native and target language to inspecting the actual language learning (Ellis et al., 1984). In error analysis the learners' deviations from the target language were no longer contrasted to the first language, but the comparisons were made between the production of the target language and the target language itself (Gass and Selinker 2008). The learner language or interlanguage that learners build based on environmental data is nowadays seen as the learner internal linguistic system, that it has its own rules and conventions and is therefore worth to be studied on its own right (James, 1998; Van Patten and Benati, 2010). Thus errors learners make are not anymore regarded as imperfection (Gass and Selinker, 2008), and the corrections teachers provide to students are considered as opportunities for developing students learning, that makes teachers be more careful about the corrective feedback they use in classrooms.

Corrective feedback (CF) as it is a very critical issue in learning languages, has been investigated and studied from a variety of different standpoints. Researchers have found out different answers to practical questions related to the issues such as how and when to correct students (Lyster and Ranta, 1997; Ellis et al., 2006; Surakka, 2007; Rahimi and Dastjerdi, 2012; Taipale, 2012).

Most of the studies give more attention to the importance of feedback, ways of providing and receiving feedback as well as what the effect of feedback on students' writing (Lee, 2005; Noora, 2006). What have been neglected in such studies, is the preferences and attitudes of the learners and teachers towards error correction (Katayama, 2007). Understanding these preferences is of paramount importance in the teaching and learning process.

According to the relevant literature on teachers' and students' preferences and attitudes towards error correction, many studies show that while teachers and students share such common views as the importance of error correction and the types of errors that need correcting, there exist considerable discrepancies as to the techniques of error correction (Lee, 2005; Wang, 2010). For instance, students favor the overall correction, whereas teachers do not. In his research, Noora (2006) found that FL students favored a focus on form, but some discrepancies appeared in teachers' beliefs. In a comparison of students' and teachers' beliefs, 
Diab (2005) also found various discrepancies between EFL instructors' and students' preferences for error correction and paper-making techniques. Such differences between students' and teachers' expectations and views about feedback can result in unsatisfactory learning outcomes (Riazi and Riasti, 2007; Katayama; 2007).

However, research on teachers' preferences for corrective feedback was mainly conducted on written and not the oral corrective feedback. And even in this area research has shown to be controversial. As reported in different studies (Diab, 2005; Hyland, 1998; Jeon \& Kang, 2005; Amrhein \& Nassaji), the conflict and uncertainty regarding the effectiveness of various types and amounts of WCF (written corrective feedback), as well as the incongruity between students' and teachers' perceptions regarding WCF are pedagogically problematic. For example, teachers may be providing a particular kind of WCF but students may not agree with it. As noted above, if students do not agree that a certain type of WCF is needed, then they will be less likely to use it.

Therefore, it is important for both teachers and students to be clear on what works for them and how. Thus, several researchers have suggested that in order for feedback to be effective, there needs to be an agreement between teachers and students, and perhaps students' expectations need to change to better fit what is most effective in developing their writing skills (e.g., Diab, 2005; Hyland, 1998; Jeon \& Kang, 2005; Leki, 1991; Plonsky \& Mills, 2006; Raimes, 1991; Saito, 1994; Schulz, 1996, 2001).

In conclusion, this study will focus on teachers' preferences attitudes towards error correction since these attitudes have a great impact on the entire learning process.

To do so, the following research questions are investigated in this paper:

1. Do teachers correct different types of errors namely grammatical \& phonological errors with the same technique?

2. Do teachers allow peer-feedback in class? How often? For what types of errors?

3. Do teachers use different types of corrective feedback for students with different proficiency levels?

\section{Method}

\section{Participants}

To accomplish the afore-mentioned objectives, the study was conducted with 62 English teachers who were chosen randomly from different language institutes in Shiraz, Iran. 30 of the teachers were females, and 32 males, aging from 24 to 47, and one was a 62 year-old teacher. All teach based on the communicative approaches so that they allowed high amounts of student interaction in class. They have at least had 4 years of teaching experience in different language institutes. Their first language was Farsi, except 2 of them who were native English speakers. The participants had their B.A, M.A, or Ph.D degrees in English translation, Linguistics, English literature or TEFL. Just one of the teachers had majored in food industry. 


\section{Instrument}

To achieve the goals of the study which have been addressed previously, a questionnaire was employed as data collection instrument. At first the six types of corrective feedback suggested by Lyster and Ranta (1997) were introduced through 6 short conversations. Each conversation started with a student's ill-formed sentence, followed by the teacher's corrective feedback of one type. These types of corrective feedback include:

1. Explicit correction: the teacher provides both positive and negative evidence by clearly saying that what the learner has produced is erroneous (Lyster and Ranta, 1997).

2. Recasts: teacher's reformulation of all or part of a student's utterance, minus the error (Lyster and Ranta, 1997).

3. Clarification requests are the type of feedback that carries questions indicating that the utterance has been ill-formed or misunderstood and that a reformulation or a repetition is required are identified as clarification requests (Lyster and Ranta, 1997).

4. Metalinguistic feedback: comments, information, or questions related to the wellformedness of the student's utterance, without explicitly providing the correct form (Lyster and Ranta, 1997).

5. Elicitation: a correction technique that prompts the learner to self-correct (Panova \& Lyster, 2002).

6. Repetition which is the teachers or interlocutors' repetition "of the ill-formed part of the student's utterance, usually with a change in intonation" (Panova \& Lyster, 2002, p.584).

After introducing the 6 types of corrective feedback some close and open-ended questions were asked. The closed-ended questions were about the most preferred type of corrective feedback provided following different types of errors (phonological, grammatical, lexical). The open-ended part asked if they allowed peer correction in class, and if they did, how often, and for what sort of error and for which levels. The next open-ended question asked if they correct students at different proficiency levels differently. The items at the end of the questionnaire were to ask the participants some biometric data to provide some information about their age, gender, years of teaching experiences and the different levels they teach.

\section{Procedures}

The questionnaire was administered to the participants to elicit the information by the researcher in language institutes. Before starting to distribute the questionnaire; the participants were asked if they were eager to participate. Their participation was voluntary and the survey was anonymous. Also they were informed that they were free to withdraw at any time and for any reason. Next, the instruction was given orally to make sure that each participant can understand what is meant by the examples about the different types of corrective feedback and 
also how to answer the items. They were also informed that they could skip any questions that they would feel uncomfortable to answer. They however, were given no additional information relevant to the nature of research project. It was also emphasized that there were no right or wrong answers and that they were only asked to report their own opinions as honestly as possible.

\section{Conclusion}

As mentioned earlier, the study aimed at finding the EFL Iranian teachers' preferences for corrective feedback types, their perspectives and personal ideas were taken into account. The results regarding the first research question revealed that 43 of 62 teachers have chosen the same techniques for correcting students' grammatical and phonological errors. Among which the most favored type was recast, which was selected for corrective feedback following grammatical errors by 24 teachers, and following phonological errors by 20 teachers. And the least favored type was explicit type of corrective feedback that none of the teachers have said to use it following grammatical errors and 2 of them said they use it following phonological errors. The results were consistent with the research conducted by Chaudron (1977), Panova \& Lyster (2002), Yoshida (2008) \& Park (2010). The findings showed that recasts were the teachers' most favored corrective feedback type over elicitation and metalinguistic feedback due to the time limitation of classes and their awareness of learners' cognitive styles.

Regarding the second research question 13 of 62 teachers have stated some reasons for opposing the use of peer-feedback in classrooms. 3 of the teachers said they just don't find it useful, 2 said there is not enough time for that, 2 others stated that it is useful just for male students, and 2 of them believed that just for advanced classes it might be helpful. Some other reasons to refuse the use of peer-feedback in classrooms were that the teacher felt he should correct the students himself and on the spot. Another participant preferred to ask the most proficient in class to correct others.

However, the 39 other teachers all have claimed to encourage peer-feedback in their classes as they find it helpful to leaning. 14 of the teachers believed that peer-correction is more helpful when follows grammatical errors, 7 believed it is beneficial for both grammatical and phonological errors, others believed it is fruitful in every situation.

With regard to the third research question, different ideas were contended by the participants. They all believed that proficiency level is just one reason to make them decide how to correct the learners, but many other factors are also crucial. 11teachers cited that they prefer to provide adults with delayed feedback not to hurt them. The ideas regarding this question were rather controversial, some believed explicit types of correction are more suitable for kids, however some said more implicit types are better for kids. Some others stated that for beginner levels the corrections should be on the spot, although others disagreed. The results have been in line with the previous research conducted by Acker (2000). The results indicated 
that the most frequent reason given for not wanting correction was the negative impact of correction on students' confidence and motivation. From the opinions of theorists such as Doughty (2001) or Bartram and Walton it is possible to see that it is difficult to arrive at any general satisfactory conclusion regarding delayed and immediate correction.

The controversy also was parallel to previous research of Fukuda (2004) who concluded that the effective error treatment is extremely complex since it depends on many factors, including students' needs, preferences, personalities, proficiency levels, and motivation.

By investigating both teacher and student preferences and finding the discrepancies, educators and teachers can have more fruitful learning classrooms with motivating students by doing what they like to do. By finding about the beliefs behind what teachers do in classrooms, teacher educators can better tell teachers how to correct students based on what they believe to be correct. This paper can therefore shed some light on what teachers think of corrective feedback they provide students with in language classrooms.

\section{References}

Ancker, W. (2000). Errors and corrective feedback: Updated theory and classroom practice. English Teaching Forum, 38(4), 20-24.

Bartman, M. \& Walton, R. (1991). Correction. A positive approach to language mistakes. Hove: LTP.

Brown, H. D. (2004). Principles of Language Learning and Teaching. Foreign Language Teaching and Research Press.

Chaudron, C. (1977). A description model of discourse in the corrective treatment of learners' errors. Language Learning, 27, 29-46.

Diab, R. L. (2005). Teachers' and students' beliefs about responding to ESL writing: A case study. TESL Canada Journal, 23, 28-43.

Doughty, C. (2001). Cognitive underpinning of focus on form. In Robinson (Ed.) cognition and second language instruction (pp. 206-257). Cambridge: Cambridge University Pres s.

Ellis, R., \& Sheen, Y. (2006). Re-examining the role of recasts in L2 acquisition. Studies in Second Language Acquisition, 28(4), 575-600.

Fukuda, Y. (2004). Treatment of spoken errors in Japanese high school oral communication classes. Master's thesis, California State University, San Francisco.

Gass S., \& Selinker L., (2008). Second language acquisition: an introductory course (3rdEdition). Routledge: New York. 
Hyland, F. (1998). The impact of teacher written feedback on individual writers. Journal of Second Language Writing, 7, 255-286.

James, C. (1998). Errors in language learning and use - exploring error analysis. Edinburgh: Harlow

Jeon, M., \& Kang, I. (2005). Investigating student preferences in error correction in Korean-language teaching. American Association of Teachers of Korean, 5 (10), Retrieved from http://www.aatk.org/html/KLA10/MJeonIKang.pdf

. Katayama, A. (2007). Japanese EFL Students' Preferences toward Correction of Classroom Oral Errors, Japanese Language and Learning, 41(1), 61-92.

Lee, I. (2005). Error correction in the L2 writing classroom: What do students think? TESL Canada Journal, 22 (2).

Leki, I. (1991). The preferences of ESL students for error correction in college-level writing classes. Foreign Language Annals, 24, 203-218.

Lyster, R., \& Panova, I. (2002). Patterns of corrective feedback and uptake in an adult ESL classroom. TESOL Quarterly, 36(4), 573-595.

Lyster, R., \& Ranta, L. (1997). Corrective feedback and learner uptake: Negotiation of form in communicative classrooms. Studies in Second Language Acquisition, 19, $37-66$.

Noora, A. (2006). Iranian undergraduate's non-English majors' language learning preferences. GEMA Online Journal of Language Studies, 33(8), 2-14.

Park, H. S. (2010). Teachers' and learners' preferences for error correction. Unpublished Ph.D Thesis. California State University.

Riazi, A. \& Riasati, M. (2007). "Language Learning Style Preferences: A Students Case Study of Shiraz EFL Institutes.” Asian EFJ Journal, 9(1), 6.

Wang, P. (2010). Dealing with English Majors' Written Errors in Chinese Universities. Journal of Language Teaching and Research, 3, 194-208.

Yoshida, R. (2008). Teachers' choice and learners' preference of corrective feedback types. Language Awareness, 17(1), 78-93. 